\title{
Values and Objectivity in Science: Value-Ladenness, Pluralism and the Epistemic Attitude
}

\author{
Martin Carrier
}

Published online: 6 June 2012

(C) The Author(s) 2012. This article is published with open access at Springerlink.com

\begin{abstract}
My intention is to cast light on the characteristics of epistemic or fundamental research (in contrast to application-oriented research). I contrast a Baconian notion of objectivity, expressing a correspondence of the views of scientists to the facts, with a pluralist notion, involving a critical debate between conflicting approaches. These conflicts include substantive hypotheses or theories but extend to values as well. I claim that a plurality of epistemic values serves to accomplish a non-Baconian form of objectivity that is apt to preserve most of the intuitions tied to the objectivity of science. For instance, pluralism is the only way to cope with the challenge of preference bias. Furthermore, the plurality of epistemic values cannot be substantially reduced by exploring the empirical success of scientific theories distinguished in light of particular such values. However, in addition to pluralism at the level of theories and value-commitments alike, scientific research is also characterized by a joint striving for consensus which I trace back to a shared epistemic attitude. This attitude manifests itself, e.g., in the willingness of scientists to subject their claims to empirical scrutiny and to respect rational argument. This shared epistemic attitude is embodied in rules adopted by the scientific community concerning general principles of dealing with knowledge claims. My contention is that pluralism and consensus formation can be brought into harmony by placing them at different levels of consideration: at the level of scientific reasoning and at the level of social conventions regarding how to deal with claims put forward within the scientific community.
\end{abstract}

This article was completed while I was visiting the Max-Planck Institute for the History of Science in Berlin. Many thanks go to my host Hans-Jörg Rheinberger. I am grateful to audiences in Bielefeld, Greifswald, London Ontario, Berlin, and Wuppertal for many helpful responses that did much to improving the argument.

M. Carrier $(\bowtie)$

Department of Philosophy, Bielefeld University, P.O.B. 100 131, 33501 Bielefeld, Germany

e-mail: martin.carrier@uni-bielefeld.de 


\section{Introduction}

My intention is to clarify the nature of scientific objectivity and of the characteristics of epistemic research, also known as fundamental research or academic research. The underlying motive is to illuminate the distinction between epistemic research and application-oriented research in methodological respect. In the pertinent literature, complaints to the effect are frequently raised that application-orientation is liable to hurt central virtues of doing research, as they are epitomized in fundamental research (Schweber 1993; Ziman 2002 , 2003). I won't deal with such claims directly but rather with how to test them. If the bearing of such objections is supposed to be examined, a distinction between applicationdriven research and fundamental or epistemic research is called for. Yet the viability of such a distinction is often denied. Many critics claim that application-oriented and fundamental research are inextricably interwoven and cannot be unraveled. I wish to undermine this inseparability claim by outlining essential features of fundamental or epistemic research. I hasten to add that I want to have this distinction used for analytical purposes only. I grant at once that a given research project in the sciences can be applicationoriented and epistemic in character at the same time (Stokes 1997, pp. 8-17, 71-75). The distinction between applied and epistemic is meant to be non-exclusive. What I seek to elaborate is a sort of ideal type of epistemic research that can be used to classify or evaluate the plethora of non-ideal or mixed cases that dominate the research practice.

I claim that epistemic research in science can be reconstructed by appeal to values. I explore the role of values in the test and confirmation procedures of science (also known as the context of justification) and discuss the role and influence of epistemic and non-epistemic values. The trouble with values is that they are mostly partisan and non-universal and are thus feared to undermine the objectivity of science. I contrast a Baconian notion of objectivity, expressing a detached stance of scientists and a correspondence of their views to the facts, with a pluralist notion, involving a critical debate between conflicting approaches. These conflicts include substantive hypotheses or theories but extend to values as well. I argue that pluralism serves to accomplish a non-Baconian form of objectivity that is apt to preserve most of the intuitions tied to the objectivity of science. However, scientific research needs to be characterized by additional factors, e.g., by the willingness to subject one's claims to empirical scrutiny and to respect rational argument. In order to account for such features of scientific practice, appeal to shared epistemic goals is necessary. This is where pluralism is bound to come to an end. This shared epistemic attitude expresses a commitment to the gain of objective knowledge and is embodied in rules adopted by the scientific community concerning the procedures of examining assumptions. These rules do not address the evaluation of scientific hypotheses directly but rather the social processes that govern the test and confirmation practices in the scientific community. Controversy and strife is as characteristic of research as is unforced consensus formation. My claim is that the two features can be brought into harmony by placing them at different levels of consideration: at the level of scientific reasoning and at the level of social conventions regarding how to deal with claims put forward within the scientific community.

\section{Objectivity and Values}

Max Weber is often credited with conceiving the notion of a value-free science. Weber claimed that science can never enunciate binding norms or ideals. Values can be studied in a systematic fashion, to be sure: conceptual relations between values can be analyzed, the 
consequences and side-effects of adopting certain values can be determined or the appropriateness of means for the realization of certain ends be examined. However, science cannot justify or disprove value judgments (Weber 1904, pp. 148-157).

Underlying this conception is a clear distinction between facts and values, based on David Hume's insight that values do not follow from facts: 'is' does not imply 'ought' (Hume 1739/1740, p. 469). Given this fact-value dichotomy, the idea of restricting science to the realm of the factual expresses a commitment to objectivity. Objectivity in the metaphysical sense means that science represents the pertinent objects and processes truthfully; science captures the nature of these items. By contrast, objectivity in the methodological sense means justified intersubjective agreement. All competent observers agree on ascribing certain properties to an object; the process of assessing claims is nonarbitrary and non-subjective (Longino 1990, pp. 62-63; 1993, p. 261). Objectivity in the metaphysical sense is rooted in objectivity in the methodological sense: only by following demanding examination procedures can we hope to capture the nature of objects. That is, science is the royal road toward knowledge of the world-if anything is.

Both notions of objectivity agree in that objectivity is achieved by going beyond what is merely subjective. Objective features are part of the phenomena and thus independent of our wishes and fears, and of what we appreciate or detest. By contrast, value-judgments are subjective and depend on our choice. They express individual or social commitments and gain their binding force by agreement or convention. As a result, it is not implausible at first sight to regard the intrusion of values as a threat to scientific objectivity.

The notion of objectivity was strongly shaped by Francis Bacon. Bacon's notion of objectivity emphasizes representing the phenomena adequately and being neutral to and detached from the research object. The pertinent slogan is to relinquish one's prejudices. This means that researchers are advised to avoid any premature formation and one-sided examination of hypotheses and to include alternative perspectives, potential counterexamples and additional influences into their considerations (Bacon 1620, Bk. I, §§ 37-65, 68). This notion of objectivity is individual-centered; it embodies the early modern ideal of exploring questions by utilizing one's own senses. This attitude grew out of the distrust the pioneers of the scientific revolution harbored vis-à-vis the science of the past. Scientists are required to look into the matter themselves.

Baconian objectivity does not demand that research be conducted by scientists in isolation. Rather, Bacon advocates the division of labor that is so characteristic of large parts of science today. It is perfectly all right that the various features and facets of a phenomenon are disclosed by a number of researchers (Bacon 1620, Bk. I, § 113). Thus, Baconian science is a social undertaking, to be sure, but not necessarily so. Research can be distributed among various scientists provided that they uniformly apply Bacon's canon and don't let their subjective predilections or aversions enter their scientific judgments. No particular significance is credited to the interaction among scientists. Further, all valuecommitments, at least those that transcend the epistemic obligations of Bacon's rules of reasoning, tend to distort the objectivity of science. This notion of objectivity resists any integration of values apart from the appreciation of knowledge and the commitment to Bacon's rules.

\section{The Role of Epistemic Values in Science}

However, it is clear that doing research today appeals to values in a large number of ways and respects. It has been frequently emphasized that the facts in and by themselves do not 
determine how they are to be rendered or interpreted. For instance, one way of capturing data is to simply itemize the phenomena observed, an alternative option is to ascend to observational generalizations, a third possibility is to subsume such generalizations under higher-level theoretical principles. Each of these modes exhibits characteristic virtues and liabilities. Cataloguing observations renders the facts with high accuracy and certainty, while summarizing them by observational generalizations avoids the unwieldiness of the first approach and yields a more parsimonious account. Invoking theoretical principles provides a more unified and coherent picture of an entire realm of experience but suffers in general from a reduction in accuracy. Typically, descending from the principles to the concrete phenomena demands adjustments by adding more specific hypotheses or introducing correction factors (see Sect. 4). ${ }^{1}$

Underdetermination problems of this kind can be addressed and in part solved by invoking values called 'epistemic' or 'cognitive' (McMullin 1983, pp. 6-8, 18-20; Carrier 2008a, pp. 274-275), a designation I take to emphasize the gain of significant knowledge or understanding (rather than truth simpliciter, see below). Kuhn initiated this approach with sketching a 'list model' for assessing scientific theories; his list of values includes accuracy, consistency, broad scope, simplicity, and fruitfulness (Kuhn 1977, pp. 321-322). Kuhn's list is by no means exclusive. Helen Longino suggests empirical adequacy, novelty, ontological heterogeneity, complexity of interaction, applicability to human needs, and decentralization of power as standards for assessing scientific theories (Longino 1995, p. 385$)^{2}$

Epistemic values play a twofold role in science. They express requirements of significance and confirmation. Significance requirements are influential on the choice of problems and the pursuit of theories in epistemic research, confirmation requirements contribute to assessing the bearing of evidence on theory. As to the first role, epistemic values delineate the goals attributed to science as a knowledge-seeking enterprise. For instance, scientists strive for knowledge that is valid in a wide domain; they appreciate universal principles. At the same time, they rate precision highly and correspondingly hold quantitative relations in esteem. Further, scientists search for understanding which is often expounded in terms of the coherence of the views entertained. Knowledge may encompass isolated pieces of information, but understanding demands relations of fit or mutual support among the knowledge elements.

Accordingly, epistemic significance is determined by epistemic values. Such values serve as a non-triviality condition of knowledge claims and establishes relevance relations. A feature underlying many such evaluations is logical content or the dependence of other parts of the system of knowledge on the item in question. For instance, since scientists aim for broad scope, a research question that affects large-scale generalizations comes out as

\footnotetext{
${ }^{1}$ Underdetermination is not the only route to value-ladenness. Heather Douglas (2000) has convincingly argued that many processes of decision-making in science are interspersed with values.

${ }^{2}$ Here are two more lists. Willard V.O. Quine and Joseph Ullian feature, among other criteria, 'conservatism' (i.e., coherence with the background knowledge), generality (i.e., broad scope), and 'refutability' (i.e., empirical testability) (Quine and Ullian 1978, pp. 66-80). Peter Kosso gives a different, but related cluster of cognitive criteria which includes, among others, "entrenchment" (i.e., coherence with the background knowledge), precision, and generality (Kosso 1992, pp. 35-41). In addition to this co-existing multiplicity, historical changes in science affect the value-commitments of the scientific community. A disadvantage of such lists is their lack of coherence; items can be abandoned or replaced by others without creating inconsistencies. An alternative approach to judging scientific theories is to devise more systematic methodological theories that identify such features of excellence from a unified point of view. Examples are Lakatosianism and Bayesianism that give a coherent account of methodological distinction and thus provide a rationale as to why certain features and not others are to be preferred (Carrier 2008a, p. 284).
} 
epistemically significant. Fundamental questions are characterized by the fact that the truth value of a large number of other propositions are affected by their resolution. This is why examining more fundamental or more universal claims is supposed to possess epistemic value. By contrast, establishing logically isolated propositions (such as ascertaining the number of leaves of a given tree at a certain time) is considered pointless. But logical content is not always a good measure of significance. For instance, accuracy is an epistemic value and may thus be taken as an indication of significance, but tends to reduce the scope of a generalization and thus to diminish the number of affected propositions. Accuracy becomes relevant in the logical-content sense if the resolution of a controversial issue is affected by the precise numbers. In such cases, the truth values of a considerable number of other statements hinges on getting the numbers right. Yet the epistemic distinction between prediction and retrodictive and post hoc explanation cannot be captured in terms of differences in logical content. As a result, epistemic values are the essential yardstick of epistemic significance, and in some, but not all, cases assessments of epistemic significance can be traced back to logical content.

Epistemic significance is employed here as a notion of objective bearing. It is not intended to refer to psychological states and to specify what looks interesting to many scientists. It is rather meant to indicate what appears significant to the scientific community. This notion is epitomized in the actual choices made. The claim is that research items that are significant in this sense tend to be picked by the scientific community.

Second, epistemic values are employed in assessing how well hypotheses are confirmed by the available evidence. They are used for singling out acceptable hypotheses. Acceptance can either mean the belief that a hypothesis (or model or theory) is sufficiently confirmed or the recognition that the hypothesis is useful for building further theoretical considerations on it. Hypotheses need to exhibit certain virtues over and above fitting the phenomena in order to be included in the system of knowledge. Regarding confirmation, appeal to non-empirical values amounts to favoring certain forms of agreement with the observations over other forms. This is revealed by the sketch of list models above. If two accounts are empirically equivalent and one of them uses a large number of unrelated hypotheses while the other one appeals to a few overarching principles, the commitment to coherence (or simplicity or broad scope) favors the latter approach. Assessed in light of this value, the evidence favors the more unifying treatment-even if the two approaches are empirically equivalent. The scientific community resorts to such values for making a choice between empirically indistinguishable alternatives. Scientists break the tie between rival accounts that conform to the data to approximately the same degree by appeal to virtues that transcend the requirement of empirical adequacy (Carrier 2011). ${ }^{3}$

On the whole, epistemic values provide measures of epistemic significance and standards of credibility that hypotheses need to satisfy in order to pass as acceptable. Such

\footnotetext{
3 John Norton advocates the view that an underdetermination thesis of this sort is self-defeating: Demonstrable observational equivalence suggests that the two alternatives in questions are merely notational variants of the same theory (Norton 2008, pp. 33-36). However, Norton requires in-principle empirical equivalence whereas I take it that temporary indistinguishability (or transient underdetermination) is sufficient for driving the crucial point home that theory choices are sometimes made prior to the emergence of empirical superiority of one of the alternatives at hand. Norton's position is based on incorporating virtues that go beyond the conformity to experience in the notion of confirmation. Norton's notion of confirmation includes plausibility considerations (Norton 2008, pp. 29-32). I grant at once that it can hardly be demonstrated that to each theory an alternative can be constructed that is genuinely distinct conceptually, provably equivalent empirically, and equally plausible. The argument employed here works with a much weaker notion of empirical equivalence. The latter only requires contingent empirical indistinguishability which needs neither to be permanent nor demonstrable nor include elements of inductive support.
} 
values are insufficiently characterized as being 'truth-related' or 'truth-conducive'. They may possess these properties but their distinction is to adumbrate which kind of truths we consider worthwhile. For instance, virtues like broad scope express a preference for overarching theoretical principles, values like accuracy exhibit a penchant toward more limited generalizations that retain close contact with the observations. Such values point in specific epistemic directions.

Critical as epistemic values are in the process of confirming and adopting hypotheses, they fail to direct this process unambiguously. Kuhn was the first to call attention to this insufficiency of epistemic values which arises from the tension between different such values in their application to concrete cases (Kuhn 1977, pp. 322-325). Here is an example of this 'Kuhn-underdetermination', as I call this room for judgment created by ambiguous epistemic values (Carrier 2006, pp. 98-107; 2008a, pp. 276-278). Consider the competition between Hendrik Lorentz's classical electron theory and Albert Einstein's special relativity theory around 1910. Lorentz's theory had a larger domain of application than Einstein's. It included electrodynamic phenomena that were accounted for by Einstein as well, but also interactions between charges and fields (such as the normal Zeeman effect, i.e., the split of spectral lines in a magnetic field) that were later incorporated into quantum mechanics. Special relativity excelled in explanatory power (or 'simplicity' or 'parsimony') in the sense that a few principles covered a wide range of phenomena. The reason is that Lorentz assumed certain effects and subsequently introduced mechanisms that prevented the observability of these effects. He needed to invoke a sort of conspiracy of nature who veils her true workings to the meddlesome gaze of humans. Einstein did away with both the effects and their compensation so that special relativity outperformed classical electron theory with respect to explanatory power. Invoking the virtues of broad scope and explanatory power leaves us without a clear rank-order of the two theories in question (Carrier 2008a, pp. 281-282).

The underdetermination of judgment is even more striking if a conflicting set of epistemic values is employed. Consider the tension between coherence and progress. One may either appreciate the preservation of what has been achieved before as a primary goal or chiefly emphasize venturing into new ground. For instance, the general relativistic program of geometrizing gravitation involved a rupture with the Newtonian view on gravity and shifted gravity away from the other natural forces. Gravitation adopted a unique position as a geometrized interaction. There was a loss of coherence but a gain in empirical adequacy and predictive power. As a result, different sets of epistemic values suggest different judgments about confirmation when the merits of particular theories are to be compared.

\section{The Non-Empirical Nature of Epistemic Values}

I suggested in Sect. 3 that epistemic values are non-empirical. I wish to defend this contention more systematically and argue that at least the fundamental epistemic values are inevitably non-empirical and cannot be buttressed by considering how well scientific theories that incorporate such values are doing in empirical respect. It is true, some such values can be assessed by appeal to the empirical success of theories that appear distinguished in their light. Sometimes we learn by interacting with nature which values can be upheld and which measures are called for to implement them. A well-known example is the discovery of the placebo-effect and the subsequent introduction of the methodological requirement of supplementing experimental subjects with a control group and do the tests in a double-blind manner (Laudan 1984, pp. 38-39). Such methodological considerations 
derive from applying more basic epistemic values such as well-testedness to particular empirical arrays. Further, certain values have turned out not to be realizable, which undermines their binding force. For instance, one of the traditional criteria of knowledge is certainty. Aristotle demands of knowledge that it is true and that we know it is true-i.e., that we can be certain about it. This epistemic commitment was preserved in the Scientific Revolution; it materialized in Galileo's predilection for thought experiments, in the emphasis of the mechanical philosophy on intelligibility with the accent placed on pushand-shove causation and the mechanical clock as the symbol of nature's workings, and in the Newtonian notion of 'proof by experience' (Laudan 1984, p. 61; McMullin 2001, pp. 288-289, 295-299). Science was not only required to clarify how nature operates; it was also expected to demonstrate that nature could not operate otherwise. However, the existence of deep ruptures in the course of scientific development and the non-cumulative nature of scientific change in periods of drastic alteration have revealed that scientific knowledge is and remains fallible and that certainty is unachievable as an epistemic goal. In particular, the relativity and quantum revolutions in physics early in the twentieth century have promoted the adoption of thoroughgoing revisability.

Accordingly, in the course of the continual interaction with nature, certain epistemic values were recognized as unrealizable and consequently abandoned. Unattainability of an epistemic value is an experience-based argument for discounting the value (Laudan 1984, pp. 38-40, 50-62). The question is how much weight this experience-based strategy of judging the appropriateness of values can carry. Stéphanie Ruphy has generalized this idea and claimed that the epistemic worth of values in science can always be assessed on empirical grounds. What counts as an appropriate cognitive value is decided by examining the empirical success of theories approved in their light (Ruphy 2006, pp. 210, 212). The trouble with this suggestion is that epistemic values contribute to defining the notion of empirical success in the first place. Let me explain three alternative epistemic commitments that regard different modes of agreement with the phenomena as empirical success.

Consider the methodological transition from inductivism to hypothetico-deductivism. Bacon constrained science to observables, and demanded that hypothesis formation needs to be guided by observation (Bacon 1620, Bk. I, §§ 18-19, 22, 26, 36). In the nineteenth century, scientists and philosophers of science increasingly realized that their theories did not fit into this inductivist framework. For instance, both the competing wave and particle accounts in optics employed concepts (such as light wave or light particle) that did not correspond to direct observation. As a result, the methodological commitment of the scientific community switched to hypothetico-deductivism, in whose framework it was legitimate to posit theoretical hypotheses which gained their justification from the accord of their consequences with observation (Laudan 1984, pp. 56-60). Yet the inductivist commitment to unmediated and complete testability had not been proven infeasible. Rather, the scientific community had decided to settle on theories exhibiting a higher explanatory power-which demanded concepts that were more detached from the phenomena and were able for this reason to cover several, prima-facie distinct phenomena.

This example shows that the adoption of epistemic values may involve a comparative evaluation of conflicting goals. The scientific community could have held fast to its prior inductivist orientation and sacrificed the theoretical hypotheses in question. This would have meant denying that the explanation of phenomena accomplished by such hypotheses count as empirical success. One could have argued within the inductivist framework that the means used for arriving at the pertinent explanatory achievements are not viable. Suppositions about light particles or light waves would have been taken to be purely 
speculative and not to be produced in line with the received methodological canon of unprejudiced observation and careful generalization. It is the notion of empirical success itself that is contentious in this case.

The same conclusion accrues from another example, namely, the issue whether experimentation is a legitimate means for gaining knowledge. The legitimacy of experimentation was introduced by the Scientific Revolution as a methodological novelty in contrast to medieval Aristotelianism. Within the latter framework, experimental intervention was regarded as a distortion of the natural course of events and seemed unsuitable for this reason to elucidate the phenomena of nature. Johann Wolfgang von Goethe's criticism of Newtonian optics proceeded along the same lines. Goethe reproached Newton's experiments for forcing nature to respond in contrived ways so that scientists are misled in their interpretation. Experimentation is tantamount to torturing nature with the result that she gives deceptive answers. In order to obtain significant and trustworthy evidence about nature, she must be allowed to speak unconstrained. Put more concretely, scientists should limit themselves to registering what nature produces on her own; intervening in nature produces only specious and deceptive results. ${ }^{4}$ Again, it is the notion of empirical success that is under dispute.

Third, there is, in general, a trade-off between universality and accuracy. It is true, universal theories may provide accurate predictions (such as in the celebrated case of the ultra-precise prediction of the anomalous magnetic moment of the electron by quantum electrodynamics), but the more frequent relation is that the universality of a generalization is purchased at the expense of reduced accuracy. Several strategies are possible for coping with this predicament which involve a commitment to conflicting epistemic values. The first strategy might be called 'Platonic'; it consists of emphasizing universal features while disregarding individual deviations as insignificant. What matters are the essential characteristics of nature, not the accidental fluctuations, and the former are distinguished by their universality. So lack of precision is accepted because it is deemed immaterial to the proper notion of empirical success, namely, discovery of the comprehensive traits that underlie the whole of nature. By contrast, an alternative approach is occasionally connected with Aristotelianism. Aristotelianism in this sense (as suggested by the Categories, see Carrier 2010, p. 168, 183) emphasizes the epistemic value of accuracy and underscores the differences among processes and entities of the same kind. Particulars are granted prime importance, and universals are considered as classes of particulars all of which differ from one another on close inspection. Generalizations are of instrumental value only. They fail to uncover the essence of the phenomena which rather lies in their uniqueness and their richness in detail. Stretched to its extremes, an Aristotelian approach in this sense would welcome tailor-made models for each specific phenomenon. As a consequence, such an approach would not accept sweeping Platonic generalizations as empirical success in the first place. By contrast, Aristotelianism would be prepared to adopt, say, the use of ten hypotheses for explaining ten phenomena, each of the former covering one of the latter, whereas Platonism in the sense considered here would refuse to accept any such account as empirical success (Carrier 2011, pp. 199-201).

There are many approaches that attempt to strike a balance between these two extremes. The approach usually employed in science, for instance, appeals to generalizations or universal features in order to construct the conceptual backbone of the models used for explaining the phenomena. But matching the data requires including specifics of the

\footnotetext{
${ }^{4}$ Carrier (1981). It worth noting in passing that Goethe in his actual exposition of his anti-Newtonian color theory employed a large number of experiments. Only in his polemics against Newton did he censure the utilization of experiments.
} 
situation at hand as well. As a result, observational regularities without theoretical foundation or pragmatic moves like plugging in unexplained corrections and piecing together incongruous parts are current in constructing models. It is only by means of such local adaptations that the models become empirically adequate. Yet they continue to be conceptually shaped by higher-order theories (Carrier and Finzer 2010, pp. 88-90).

The upshot of considering three disparate approaches to seeking knowledge is that we are the ones who make a choice of the kind of knowledge we prefer. There is room for coping with experience by resorting to accounts of different kinds that implement different sorts of epistemic values. As a result, it is up to us to enrich the notion of empirical success beyond agreement with the evidence. This is achieved by adopting epistemic values that, consequently, serve to define what empirical success is all about. For this reason, the suitability of epistemic values cannot be judged by examining the empirical success of theories that implement these values. Adhering to some such values is tantamount to denying that instances of empirical success, as claimed by advocates of a rival set of values, can be regarded as empirical success in the first place. Appeal to experience in the issue of what legitimately counts as empirical success is circular or begs the question. Epistemic values are non-empirical or superempirical; they go beyond experience and cannot in general be based on experience alone. This is why scientific measures of success cannot be purely empirical, not even in the long run (in contrast to Solomon 2001, pp. 15-17, 33, 117).

\section{Value-Ladenness in Science}

These considerations show that epistemic values figure prominently in science. More specifically, such values play an important role in the context of justification: they delineate qualities of knowledge we consider worth accomplishing and thereby provide standards for assessing hypotheses. Yet there may be other, non-epistemic values that advise research and guide theory choice. Pragmatic virtues such as simplicity in the sense of easy handling or fruitfulness in the sense of opening up seminal lines of investigation are influential in research, too. ${ }^{5}$ A third cluster of values is utilitarian and has to do with the uses to which knowledge is put. Technological usefulness of a theory or the prospect of economic benefit tied to it are examples in point. The practical bearing of an account may favor its acceptance. Yet a significant characteristic of epistemic values is their universality; they concern the features of knowledge we consider worthwhile irrespective of the particular contexts in which the knowledge is used. By contrast, non-epistemic values are restricted to certain contexts. For instance, to all appearances, no utilitarian values are operative in endeavors to unify particle physics and the theory of gravitation or attempts to reveal the nature of dark energy. Conversely, epistemic values were lurking behind the industrial research devoted to giant magnetoresistance (the physical effect underlying present-day computer hard disks). The physical explanation of this effect was mostly accomplished within the research labs of electronics companies and improved the understanding of spin-spin coupling among electrons (Wilholt 2006, pp. 72-86). ${ }^{6}$ Epistemic values are the only kind of values that we take to express universal requirements of scientific knowledge.

\footnotetext{
5 Kuhn takes such values to be on a par with epistemic values like broad scope (see Sect. 3). Yet pragmatic virtues do not in general outline ideals of understanding.

6 As a result, I abstain from any claim about the general superiority of pure, epistemic research as compared to application-oriented research. Rather, the achievements of the latter are able to match the outcome of the former in epistemic respect (Carrier 2010, pp. 175-179).
} 
Universality of this sort is not supposed to suggest that each and every epistemic value is upheld come what may. On the contrary, I explained before that scientific communities may choose particular epistemic directions and opt for different such values. Similarly, Kuhn-underdetermination entails a trade-off between different epistemic values (see Sect. 3 ). The point rather is that some epistemic value is supposed to underlie each and every scientific endeavor, whereas it is widely considered acceptable that a scientific investigation may proceed without any non-epistemic ambition. For instance, the debate about the detrimental impact of the commercialization of science betrays the widely shared worry that the search for utility might compromise the quality of scientific knowledge. Yet no such complaints are raised when some project fails to be of practical benefit.

If values affect what is accepted as scientific knowledge, I speak of the 'value-ladenness' of science. Value-ladenness is the converse to the 'value-impact' of science which refers to the influence of scientific knowledge on the plausibility or persuasiveness of certain value judgments. An example of the latter sort was put forward by the geneticist Luigi Cavalli-Sforza who argued that humans are a young species, comparatively speaking, and genetically more closely related than other species like chimpanzees. This finding makes racism or claims of ethnic superiority less than convincing. 'Value-free science' in Weber's sense entails that no value commitments follow from adopting the system of scientific knowledge. Strictly speaking, this notion is compatible with the value-ladenness and the value-impact of science. In the first case, 'ought' is taken to be influential on 'is'; in the latter, no entailment relation from 'is' to 'ought' is claimed but rather an effect of science on those factual presuppositions on which the plausibility of certain value-attitudes rest. I am concerned here with value-ladenness: values contribute to determining what is rightly taken as a piece of scientific knowledge.

But what about non-epistemic values? Science has become an endeavor of considerable practical relevance in the past decades with the result that utilitarian values play a huge role in selecting research topics. Research in the natural sciences is supported by public and private funds on the grounds that science is regarded as a major factor of economic competitiveness. The science of today is deeply implicated in the context of application. The role science plays outside of libraries and laboratories brings in new value-considerations. As a result, non-epistemic values are clearly influential on the research agenda or the context of discovery. But what about the context of justification? Richard Rudner has developed an argument to the effect that non-epistemic values rightly enter the confirmation procedures in science. His approach was based on the two premises that assessing hypotheses is essential to confirmation and that hypotheses are never entailed by any available evidence. Accepting or rejecting a hypothesis in light of data always incurs an 'inductive risk': such decisions may produce false positives or false negatives. A high threshold level of acceptance reduces the risk of false positives but increases the hazard of false negatives, and vice versa. Rudner's suggestion is that weighing the non-epistemic consequences of these potential errors should decide about the threshold of acceptance. This is said to imply that ethical values rightly affect theory-choice (Rudner 1953).

Let me illustrate this claim with the more recent example of judging the hypothesis that climate change is anthropogenic. Acceptance or rejection is influenced by the pertinent consequences of error. The relevant false positive is that we erroneously take climate change to be of human origin with the result of superfluous investment in technology for diminishing atmospheric greenhouse gases. The relevant false negative is that we mistakenly attribute climate change to causes beyond human control and thereby refrain from taking measures. The consequences of error are unnecessary spending on sophisticated technology, for one, and making this planet a fairly inhospitable place for humankind, for 
another. This consideration suggests lowering the threshold for accepting climate change as being human-made.

However, as Isaac Levi pointed out in the debate ensuing on Rudner's thesis, this argument fails to make research appear essentially laden with ethical (or non-epistemic) values (Levi 1960, pp. 350-351, 357). First, accepting a hypothesis is not tantamount to acting on the basis of this hypothesis. The practical impact of research, upon which Rudner's argument draws, only emerges by the decision to take certain action by relying on the relevant beliefs. Yet in general, beliefs and actions are different kinds of things: the same set of beliefs can spawn different actions, and the same action can spring from different beliefs. The assumption that a vaccine is not safe can either lead to a stop of vaccination campaigns or to attempts to find an improved vaccine; conversely, the decision to continue with such a campaign may be based on the belief that the vaccine is safe or on the persuasion that the severity of the corresponding illness outweighs the risk of administering an unsafe vaccine. Second, many decisions about the acceptance or rejection of hypotheses do not have any specifiable practical import at all. Errors in identifying brown dwarfs or in classifying Assyrian ceramics are not likely to bring any non-epistemic consequences in their train. In such cases, hypotheses are assessed by appeal to their epistemic achievements only.

Still, the more general point is that the assessment of hypotheses requires balancing the risks of false positives and false negatives. Heather Douglas has emphasized that many factors in the design of a study affect its sensitivity in detecting false positives or false negatives, respectively. It is not solely the choice of a threshold of acceptance, but a lot of decisions about procedures used for providing relevant materials or classifying results that are influential on how suitable tests are to detect mistakes of either kind (Douglas 2000). As a result, Rudner's basic claim that finding the appropriate balance between false positives and false negatives demands the appeal to values has some force. However, only if the relevant research has serious ramifications into the non-epistemic world or if the relevant hypotheses are taken as a basis for certain actions, does it follow that ethical or non-epistemic values are rightly brought to bear. Accordingly, in contrast to Rudner's own intentions, his argument fails to establish that non-epistemic values are in general a legitimate part of the confirmation process in epistemic science.

Yet room for non-epistemic values in the context of justification is created by a different, indirect argument. First, as Kathleen Okruhlik has pointed out, theory choice grows out of theory comparison so that this choice depends upon the alternatives on offer. Had certain alternatives not been developed and pursued in the first place, they could not have been accepted eventually. The pursuit of theories influences the later choice of theories with eventual effects on the system of knowledge (Okruhlik 1994, pp. 201-203). Second, it is widely accepted that the research agenda is legitimately affected by non-epistemic values. We rightfully select certain items of practical importance for priority research. But since setting the agenda affects the structure of the decisions about confirmation relations that are to be made at a later point in time, nonepistemic values used in selecting research topics cannot help but influence the adoption of hypotheses.

Whatever importance is attached to a subtle relationship of this sort, in many relevant cases the research done is of practical relevance and is taken as a basis of actions. In such cases, Rudner's argument about weighing the non-epistemic consequences of different types of error licenses the importance of non-epistemic values in the context of justification. 


\section{The Pluralist Conception of Objectivity}

These considerations suggest that scientific confirmation rightly involves epistemic values and to some extent non-epistemic values. Values are influential on what we accept as part of the system of knowledge. Further, the list of models sketched in Sect. 3 suggest that a plurality of epistemic values pervade the context of justification. We are faced with a divergent collection of epistemic values and contrasting ways of bringing a given list to bear on theory choice (Kuhn-underdetermination, see Sect. 3). That is, instead of the Baconian uniformity we often witness a profound pluralism on the cutting edge of scientific research at all levels involved: theories, aims or values, and practical interests (if science in the context of application is included). I take it that the latter feature is a consequence of the former: incorporating values produces pluralism. Values tend to be contentious so that a diversity of opinion is bound to arise when value-laden judgments are passed. That is, the inclusion of values is in part responsible for the pursuit of conflicting research programs, controversies, and differences in judgment.

This is why the intrusion of values can be regarded as a threat to scientific objectivity. Value-judgments are subjective in character and cannot be ascertained by an intersubjective procedure. I wish to suggest that this threat can be alleviated by drawing on value-pluralism. In the Baconian framework, pluralism is a capital sin against the objectivity of science (see Sect. 2). But in fact, pluralism is a virtue rather than a liability. The reason is that the detached stance of Baconian objectivity is hard to adopt. When science becomes practically relevant, expertise and non-epistemic interests and aspirations are often heavily intertwined. Further, there is no way of singling out a preferred set of values from the conflicting lists of epistemic (and non-epistemic) commitments referred to before (see Sect. 3). Instead, the only way to curb the influence of specific values is counterbalancing them with diverging values. A notion of objectivity that is apt to take advantage of such a pluralist setting is centered on reciprocal criticism and mutual control. The Baconian maxim of relinquishing one's biases is abandoned; rather, different biases are supposed to keep each other in check. This social notion of scientific objectivity was introduced by Karl Popper and Imre Lakatos (Popper 1962, p. 112; Lakatos 1970, pp. 68-69). It focuses on the social interaction between scientists who reciprocally censure their conflicting approaches. This 'advocate model' (Adam 2008, p. 245) of scientific objectivity is supported by an epistemic rationale. All scientists take some assumptions for granted. These beliefs appear self-evident and as a matter of course so that they are frequently not acknowledged as substantive principles in the first place. The trouble with such unnoticed or implicit assumptions is that they go unexamined. They are never subjected to critical scrutiny. This means that if one of these seemingly innocuous claims should be mistaken, its falsity is hardly recognized.

Longino has stressed that predicaments of this sort can be overcome by drawing on the critical force of scientific opponents. They will struggle to expose unfounded principles and try their best to poke holes in one's cherished theories. And if scientists proceed in a false direction, there is a good chance that they are proven wrong by their more fortunate adversaries. Scientific controversies are an appropriate instrument for revealing blind spots, one-sided accounts and unfounded principles. Such deficiencies are best uncovered by taking an alternative position. For this reason, pluralism is in the epistemic interest of science; it contributes to enhancing the reliability of scientific results. In contrast to the Baconian notion, the pluralist approach to objectivity is essentially social. It thrives on correcting flaws by taking an opposing stance and thus demands the exchange of views and arguments among scientists (Longino 1990, pp. 75-76, 80; 1993, p. 266; 2002, p. 132; see Brown 2001, p. 187). 
Within this pluralist framework, the objectivity of science needs to be separated from the objectivity of scientists. Individual scientists need not be neutral and detached. They may be anxious to undergird or undercut some assumption in order to promote their reputation, support some world-view or bring about technological novelties. Such divergent values and goals need in no way undermine the objectivity of science. On the contrary, pursuing contrasting avenues and taking one another to task is such stuff as science is made on. In the pluralist understanding of objectivity, what matters is not to free scientists from all contentious suppositions but rather to control judgments and interests by bringing to bear opposing judgments and interests (Carrier 2008b, pp. 222-225).

Pluralism in the adoption of theoretical principles and value-commitments is much more widespread than often assumed. Feminist archeology has repeatedly criticized the androcentric perspective of traditional archeology that neglected the role of women in the prehistoric world. For instance, conventional wisdom distinguished between man-the-hunter and woman-the-gatherer. Only the work of female archeologists brought to light that data supporting the prehistoric hunting and warfare of women had been consistently ignored. Graves of women with bows or swords as grave goods had been unearthed but not been recognized as indicating the existence of women bow hunters or women warriors. It became obvious that archeologists had unwittingly invoked a family model prevalent in their own time for interpreting the excavation finds, namely, the breadwinning male and the housekeeping female. Women archeologists supplied a new perspective for making sense of the fossil remains.

I wish to make two points with this example. First, the elaboration of an alternative approach has improved science in epistemic respect. It has contributed to uncovering unsupported assumptions that had escaped notice before; it has prompted new questions and suggested new lines of inquiry. The advancement of the feminist alternative has provided a deeper and more complete understanding of the archeological evidence. Second, this epistemic benefit was not gained by dropping a one-sided approach and replacing it with a more neutral one. Rather, the alternative feminist approach involves a social model or political values as well. This time it is the role model of the working couple and of gender equality that guides theory development. We can make epistemic progress while continuing to bring value-commitments to bear.

If one looks more closely at the state of research in various disciplines, the existence of alternative approaches becomes salient. Conceptual alternatives are pursued in cosmology (regarding the existence and impact of dark matter), quantum gravitation (loop quantum gravity versus string theory), in research on cancer (cellular versus holistic accounts, Carrier and Finzer 2010) and Alzheimer's disease (amyloid versus tau versus prion hypotheses, suggesting different chief culprits). Conversely, if pluralism is absent, it needs to be fostered. If you ask research institutes sponsored by the tobacco industry about the health risks associated with smoking, the answer will be unanimous but at best misleading. The trouble is that these institutions share crucial assumptions. Commitments or interests pointing in one direction need to be counteracted by contrasting commitments and interests. There are many areas in science where the fruits of pluralism are still unreaped.

\section{The Epistemic Bearing of Pluralism}

These considerations suggest that pluralism contributes to producing features of scientific research that can count as promoting objectivity. The pluralist notion of objectivity allows scientists to proceed within the framework of their favorite research program and to bring to bear values of their own predilection. However, there are scientific studies whose 
credibility is widely taken to be impaired by a sort of bias considered inadequate or illegitimate. Such studies are not respected as sound but regarded as deeply flawed in methodological respect. Torsten Wilholt speaks of a 'preference bias', if the researchers' preferences are unduly reflected in the outcome. Research results affected by a preference bias are not trusted in the scientific community (Wilholt 2009, p. 92, 98).

For instance, relevant studies are designed such that their sensitivity to the question at hand is less high than it could be. One of Wilholt's examples concerns the examination of health risks of bisphenol $\mathrm{A}$, a substance whose biochemical effects resemble that of estrogen, by using a strain of rat that is particularly unsusceptible to estrogen. Another such case is taken from a clinical trial of a medical drug that involved comparing an intravenously administered test drug with a control medication that was orally given and thus poorly absorbed (Wilholt 2009, p. 93). A third example is provided by Sheldon Krimsky and refers to a study of the risks involved in breast implants. Silicone implants had raised a suspicion regarding associated health risks, but the relevant study examined effects of all sorts of breast implants indiscriminately and used statistical tests that were sensitive to all sorts of changes - although a positive health effect of breast implants had never been claimed. As a result, any potential harm caused by silicone implants was statistically diluted right from the start (Krimsky 2003, pp. 156-157). As Wilholt argues, such studies involve methodological flaws or epistemic shortcomings rather than the legitimate expression of values many happen not to share. Preference bias occurs when measures intended to convey epistemic trust to the relevant community fail to achieve their end (Wilholt 2009, pp. 92, 98-99).

Criticizing preference bias seems to be in conflict with a pluralist notion of objectivity. After all, the latter encourages the adoption of diverse points of view and appears to lack conceptual resources to rule out any particular such stance. Yet in fact, pluralism is able to cope with this challenge. It might look promising at first sight to hark back to the epistemic values sketched in Sect. 3. After all, they stake out what sorts of knowledge we consider worth knowing and guide the confirmation process. Nevertheless, they fail to get us very far in issues like the present ones, and the chief reason is Kuhn-underdetermination. The plurality and heterogeneity of values contained in the various lists make them unfit as a basis of the unanimous judgment of particular cases. Value pluralism extends to epistemic values; there is no agreement as to how exactly an excellent scientific hypothesis or theory should look like.

The flaw involved in testing or adopting the mentioned hypotheses needs to be captured differently. It rather has to do with the fact that the studies in question do not deal with the issues they purport to address. They do not tackle the questions they pretend to answer. In the bisphenol A case, the issue expected to be taken up was whether there is a health risk for humans involved. This question is sidestepped by picking a particularly robust strain of rat. The same goes for comparing intravenously administered drugs with orally given medication and for using statistical methods less than sensitive to detecting health risks considered relevant. The procedures used are not floppy or inappropriate in general, and this is the deeper reason why the appeal to epistemic values in general is of no avail. The procedures are highly suitable for revealing false positives, that is, they are good at ruling out the mistaken assumption that health risks exist. However, the question they purport to answer is the converse one, namely, to ascertain that false negatives are avoided. The result suggested or intimated is that no health risks exist. The methodological flaw involved here is false advertising.

The general framework is that accepting or rejecting a hypothesis in light of data always incurs an inductive risk: such decisions may produce false positives or false negatives, the erroneous adoption of a mistaken assumption or the incorrect rejection of a truthful hypothesis (see Sect. 5). Such risks often need to be traded-off against each other. There is 
no general methodological rule to determine what the right balance between the two risks is. So researchers may feel free to strike the balance in different ways. In toxicological or pharmaceutical studies of the sort mentioned, the occurrence of health risks is examined. The expected purpose of such studies is to make sure that no such risks are incurred by the persons exposed to a certain substance or treated in a certain way. The expectation is that erroneous judgments to the effect that the conditions and procedures are safe are ruled out. In other words, the expectation is that false negatives are avoided. But due to the lack of sensitivity to this question, the studies fail to achieve this aim; they rather rule out that such conditions and procedures are not prematurely barred. False advertising of this sort, I take it, underlies Wilholt's preference bias, that is, the 'undue' intrusion of the researcher's preferences in the outcome.

Preference bias can occur unwittingly or deliberately. Scientists sometimes miss the right questions but sometimes misdesign a study intentionally. In the cases mentioned, it is in the interest of the sponsors of the studies not to emphasize possible health risks, and to make the relevant conditions and procedures appear safe. In this light it is not implausible to suspect that the responsible scientists deliberately traded on the general assumption that the exclusion of false negatives is at issue in such studies. The suspicion is that they tacitly designed their study in a way that was merely apt to detect false positives. If this is true, the studies mentioned would be misleading.

Accordingly, this behavior would violate the commitment to sincerity or honesty (that David Resnik includes in his principles of the ethics of science (Resnik 1998, p. 53)) and involve a misrepresentation of the issues addressed. Such methodological flaws or fraudulence can be corrected by pluralism. A study of the kind analyzed needs to be supplemented with another one addressing the issue of false negatives. In fact, given that there is no general rule for striking a methodologically justified balance between the opposite inductive risks, pluralism is the only means for moving toward an appropriate equilibrium.

In a similar vein, the Mertonian value of 'disinterestedness' can be interpreted as being realized by the pluralism of the scientific community. Robert Merton codified a system of 'cultural values' that is supposed to be constitutive of the 'ethos of science'. Values like 'universalism', i.e., reliance on impersonal, pre-established criteria of evaluation, or 'communalism', which is linked to the imperative of free and open communication, are demanded to govern the behavior of scientists. Such values are social in that they are supposed to be inherent to the scientific community, but they also have a clear epistemic significance in that their adoption is assumed to promote the quest for truth or understanding (and thus qualify as a particular variety of epistemic values). Disinterestedness in the Mertonian sense means that science does not prefer certain research results over others. This is an institutional imperative, not a psychological factor; it addresses the community, not individual researchers, who may well be motivated to produce outcome of a certain kind (Merton 1942, p. 276). The disinterestedness of the scientific community as a whole is epitomized by the struggle between antagonistic approaches. The community is divided and for this reason does not express a joint preference as to what the quest at hand should accomplish. The pertinent requirement is to keep this pluralism alive and sufficiently broad and to strengthen it if the community tends to sink into one-sided complacency.

\section{The Epistemic Attitude and the Search for Consensus}

The two preceding sections are intended to establish that pluralism has something to contribute to promoting objectivity. In Sects. 6 and $7 \mathrm{I}$ argue that pluralism is able to 
account for intuitions tied to the traditional understanding of objectivity, namely, welltestedness, undue preference bias, and disinterestedness. However, one gap remains open. The pluralist notion of objectivity is insufficient for ascertaining on its own the objectivity of science. Pluralism is helpful and important for advancing the epistemic ambitions of science, but I claim it needs to be rooted in or constrained by what I want to call the 'epistemic attitude'. This attitude amounts to accepting the goal of gaining knowledge that is generally recognized as exhibiting relevant virtues (like the epistemic values listed before). That is to say, the belligerent pluralism constitutive of essential parts of scientific rationality is curbed or pacified by a joint striving for consensus. Pluralism remains temporary and transient; it comes to an end eventually and gives way to consensus.

In particular, we regularly observe that a period of strife and confrontation is followed by the emergence of a consensus. When the dust has settled, a convergence toward widely shared views obtains in the scientific community. Further, this consensus is achieved without external pressure. Some sort of internal mechanism appears to ensure that the plurality of contrasting and heterogeneous approaches give way to a generally accepted state of research. Uncontroversial knowledge is fairly unanimously separated from unchartered territory. Kuhn's normal science has placed this phenomenon of consensus formation in the limelight. In a similar vein, Larry Laudan (1984, pp. 21-25, 42-43), Philip Kitcher (1993, pp. 87, 344), and Harry Collins and Robert Evans (2002, pp. 240-242) recognize this typical sequence of controversy and agreement. The emergence of unforced assent is a typical pattern in science.

I have tried to make plausible in Sects. 6 and 7 that pluralism has important epistemic credentials. The prospects of a particular research endeavor are mostly uncertain and pluralism is a handy means for exploring several tacks simultaneously. But it remains to be clarified by which process the scientific community settles on a certain hypothesis or theory eventually. One option is that the large majority of empirical achievements and epistemic values point in the same direction. That is, although values such as broad scope, coherence with background knowledge, and accuracy are conceptually distinct, it may happen that they all favor one particular account. Miriam Solomon subscribes to such a view, according to which consensus in science is rare and without epistemic significance. Consensus is generated by the fortuitous convergence of a variety of factors of a diverse nature, empirical or non-empirical, cognitive or emotional, rational or social (Solomon 2001, pp. 11, 99-120). However, the eventual formation of a consensus is typical in science and distinctive of it. The repeated well-considered intellectual withdrawal that goes along with the emergence of a scientific consensus is a hallmark of scientific debates. Political and religious strife tends to continue indefinitely and is only stopped by the weariness of the fighting parties. Yet scientific controversies usually come to an end on substantive grounds. This phenomenon of giving in deliberately is a characteristic of the scientific enterprise by which it is distinguished from other intellectual fields.

For this very reason, general social mechanisms that are present in broader society cannot account entirely for this feature. I grant at once that factors such as the agreement with the wider metaphysical or sociopolitical framework or with power relations in the scientific community favor certain views and thus encourages consensus formation. Yet bearing in mind that such factors exert their influence in the general social arena as well, they cannot explain the distinctive feature of the emergence of an unambiguous state of research. So I take it that some sort of rational consideration or argument is productive here. The mechanism at work has to do with epistemic motivations and the commitment to the search for knowledge of a certain kind. It is this commitment that makes scientists inclined to defer to the better argument. 
However, what are the relevant considerations like? The epistemic values of the sort explained cannot account for the repeated occurrence of consensus. Scientists generally agree upon the epistemic values of agreement with experience and consistency; thus they are worried unanimously about anomalies. But when it comes to evaluating more specific epistemic achievements, no undivided judgment is likely to emerge (see Sect. 3). Epistemic values beyond this core set are way too diverse to make a consensus based on their influence probable. Any consensus achieved on their basis is always due to serendipity. Rather, the criteria and rules shared among scientists and suitable to produce consensus are located at a different level of consideration; they regulate how to deal with knowledge claims. What is widely shared in the scientific community is requirements as to how knowledge claims should be treated. Basic standards as regards how such claims are to be discussed in the scientific community are widely accepted. These standards, I take it, serve to characterize the 'epistemic attitude'.

The Mertonian values of universalism and communalism (in the sense of unrestricted communication; see Sect. 7) are undisputed yardsticks in discussing the merits of hypotheses in a scientific community. In a similar vein, Longino put forward procedural standards that are intended to govern the process of critical examination in science. One of her requirements concerns the need to take up criticism and to respond to objections appropriately (Longino 1993, p. 267; 2002, pp. 129-130). This requirement broadens the Popperian obligation to address anomalies and counterinstances and not to gloss over them (Popper 1957, pp. 66-69). The epistemic spirit of science is distinguished by taking challenges seriously and by trying to cope with them. This commitment ramifies into accepting the revisability of convictions and thus to relinquish dogmatism. Another one of Longino's procedural standards is 'equality of intellectual authority'. This community rule is supposed to preclude personal or institutional power playing; arguments should be appreciated independently of community hierarchies (Longino 1993, p. 267; 2002, p. 131$)^{7}$

Such procedural rules are intertwined with values, but values of a different sort, namely, social values of the scientific community. These rules address how to deal with dissenting views and opposing approaches and display a clear epistemic bearing. They are epistemic values of a particular sort. Such social values of the scientific community can be expected to be more stable than the prevalent epistemic commitments. The latter values may change as a result of interacting with nature and of attempting to cut nature at the joints (see Sect. 4). Yet the former values distinguish preferred patterns of social interaction in examining knowledge claims and thus remain unaffected by changes in the demands of what a good explanation, an excellent theory, or an illuminating experiment ought to accomplish.

I do not claim that these socioepistemic values are always respected. No norm is ever heeded without exception. Instances of premature consensus exist, that is, cases exhibiting an overly hasty agreement accomplished by a careless or otherwise inappropriate application of the rules of thorough examination. For instance, nineteenth century brain research was replete with outcomes suggesting correlations between physiological quantities such as brain weight or asymmetry between hemispheres and psychological or social features. To present knowledge, all these correlations are spurious; they rather reproduced the

\footnotetext{
7 This rule strikes a familiar chord, namely, Ludwik Fleck's claim that the scientific 'thought collective' has a democratic structure. This means for Fleck that the assessment of assumptions is subject to the scientific community as a whole in an open debate. Acceptance does not arise from an arcane and secretive process hidden from the public; by contrast, each judgment is based on evidence and arguments that are in principle accessible to everyone (Fleck 1936, pp. 114-117).
} 
prejudices of the period. Yet the agreement on the underlying principles and their outcome was widely shared. ${ }^{8}$ In such cases of rash agreement, the preceding pluralist phase of criticism and assessment was not sufficiently pronounced. Basic commitments had not been called into question and went unexamined. This shows that the issue at stake is not consensus simpliciter but justified intersubjective agreement. There is a pinch of normativity involved here. Science is supposed to aim at a consensus that has been gained through painstakingly giving heed to the procedural rules of how knowledge claims should be addressed.

Even more pronounced are individual violations of the procedural rules mentioned. Not infrequently, scientists ignore counterarguments or counterevidence. However, the point is that deficiencies and failures of this sort are noticed and registered within the scientific community. They are pointed out by critics who object to the poor quality of a research result. Such criticism reveals that the underlying value commitment is in force. It is the benefit of the social conception of objectivity that the objectivity of science is not put in jeopardy by occasional individual missteps. Rather, the scientific community as a whole is the forum of judgment.

\section{Conclusion}

These considerations are intended to suggest three conclusions. First, pluralism does not detract from scientific objectivity but is a means to achieving objectivity. Pluralism in science obtains at the level of substantive theory and at the level of values guiding the evaluation of theories. A pluralist notion of objectivity can cope with this multiplicity of approaches and is suitable to codify epistemic notions like 'unduly biased study' and 'disinterestedness'. Pluralism is a basis for passing sound epistemic judgments. However, second, there are limits to establishing objectivity by relying on pluralist antagonism alone. Pluralism fails to account for one of the salient features of scientific practice, namely, consensus formation. After a period of intensive struggle, some of the warring factions end up defeated and their approaches stop being pursued. The appeal to pluralism is unable to account for disclaimers of this sort. If a political movement encounters opposition it will repeat its points even more forcefully. Sometimes this is different in science, sometimes scientists converge in their views. To explain this element of unforced persuasion or deliberate consensus formation, appeal to some shared standards or commitments is indispensable (Adam 2008, pp. 249-250).

Third, what I take to be broadly shared in scientific communities is their epistemic attitude, that is, their commitment to the gain of objective knowledge. The relevant common ground cannot consist in common standards for judging assumptions. The only such uncontested standards are empirical adequacy and consistency, and they are insufficient for producing consensus (as the underdetermination argument shows, see Sect. 3). Further, appeal to epistemic values of the sort introduced (broad scope, accuracy, coherence, and the like) cannot be responsible for creating unanimity because these values are not shared to a sufficient degree. Criteria of assessment are too diverse and too variable within the scientific community. There are contrasting commitments brought to bear within a scientific community, and there are significant changes across historical epochs. This is why I attribute consensus formation to a different level of values. I contend that the

\footnotetext{
${ }^{8}$ Hagner 1999, pp. 251-260. See Solomon 2001, pp. 109-114 for the premature consensus on the 'central dogma'.
} 
epistemic attitude is codified in the form of procedural rules of the scientific community. The epistemic attitude does not address the process of assessing hypotheses directly; it rather concerns procedures for debating such assessments. This attitude finds its expression, in particular, in commitments like attending to dissenting views and empirical problems, taking up criticism, and granting intellectual authority on substantive grounds alone. Further, these rules are essentially social: they address how to deal with nonconformist understandings and opposing approaches. Such procedural rules for addressing substantive diversity are suitable for constraining antagonistic beliefs and to drive them toward a common position. ${ }^{9}$ This general approach is certainly not unheard of. Dissent in political or legal issues is likewise sometimes resolved by appeal to procedural rules. The claim I advance here is that the same distinction between substantive and evaluative dissent, on the one hand, and procedural agreement works in science as well. Further, these procedural values are social in that they are community rules, but they are also epistemic in that following their advice is conducive to reliability or truth, that is, epistemic goals of science.

So we need shared values, after all, but they refer to social procedures for resolving value conflicts. This distinction between different levels brings the pluralism of epistemic values into harmony with consensus formation and the shared epistemic commitment of the scientific community. In order to make strife and unanimity compatible, the relevant considerations need to be placed at different levels. Scientific research is characterized by both skepticism and divergence, on the one hand, and by unforced assent, on the other. Both features are in harmony because the former refer to the test and confirmation process and the latter to the social rules guiding this process. It is only by means of an agreement of this latter sort that research can become a collective enterprise in the first place. ${ }^{10}$ Scientific consensus formation is possible because, regardless of divergent epistemic inclinations and predilections in detail, scientists have a fundamental commitment in common, the commitment, namely, to give heed to certain rules in debating knowledge claims. Adopting such rules serves to curb subjective preferences for the sake of producing knowledge that enjoys intersubjective assent.

\footnotetext{
9 That is, I try to outline the specific characteristics of epistemic aspirations. By contrast, Longino does not recognize any in-principle difference between epistemic (or cognitive) values and social or political (or contextual) values. On her approach, the two sets of values come out as strongly intertwined with one another and they operate in the same way as legitimate standards of judgment (Longino 1990, pp. 185-194; 1995, pp. 383-384, 391-397; 2008, pp. 69-77). Longino is widely taken to have undermined or dissolved the distinction between the epistemic and the social (Wilholt 2009, pp. 96-97). In addition and going beyond Longino's approach, there is no clear account in the literature of what precisely epistemic values amount to. For instance, epistemic standards are characterized by their effect of conveying epistemic trust without making clear how this feat is performed (Wilholt 2009, pp. 98-99).

${ }^{10}$ Longino attempts to supplement pluralism with the commitment to a single set of directions that include social rules, supposed to govern the procedure of legitimate consensus formation, and shared, publicly recognized standards of evaluation (Longino 1990, pp. 76-78; 1993, pp. 266-268; 2002, pp. 128-131). I agree with this twofold picture of variety and unanimity, the difficulty is, however, that the two parts of the picture tend to be disparate and incoherent. Longino's double commitment needs additional efforts to bring its contrasting facets into harmony. The account I develop in this paper is intended to square the commitment to pluralism with the requirement of consensus formation by placing the two at different loci in the context of justification. We need a consensus on how to deal with dissenting claims and incongruent standards of evaluation. Pluralism prohibits that this consensus is located at the substantive level of judging hypotheses. By Longino's own lights, the diversity of standards of judgment or epistemic values makes them unfit for creating a common ground in assessing assumptions in science. This is why the present argument entails that this common ground is mostly provided by procedural standards.
} 
These considerations are intended to show what the epistemic commitment of scientists is all about and to illuminate, consequently, what is the standard which commercialized science can fall short of. Two sorts of pertinent failures leap to the eye, namely, a violation of communalism and of disinterestedness. As to the former, proprietary research tends to restrict access to research findings and thereby impairs the public examination of knowledge claims. Scientific results are considered as a commodity whose use is confined to those who pay. This violation of the Mertonian norm of communalism is tantamount to an infringement of the public, community-wide nature of confirmation practices that is part of the conduct of science since the Scientific Revolution. By operating behind a veil of secrecy, commercialized research revives an institutional form of erudition that is attributed to Pythagoras: science is confined to a circle of the elect few and eschews the public eye (Carrier 2008b, pp. 219-221).

Second, disinterestedness of the scientific community frequently gives way to one-sided judgments. In many instances, this bias takes the form of false advertising, as analyzed before (see Sect. 7); it is thus covered by the social rule of sincerity that requires not to deceive one's fellow researchers. Other variants of bias are much less subtle. At times, evidence indicating potential harm of drugs is simply ignored (Biddle 2007, pp. 27-30). In general, clinical studies of new drugs open up a lot of design opportunities for making them less sensitive to the kind of evidence industrial researchers would rather not want to turn up (Adam 2008, pp. 241-243).

Accordingly, giving some substantive profile to the notion of epistemic research helps pinpoint where application-oriented research may part ways with the former in methodological respect. What is worrisome about parts of application-oriented research is not the lack of any specific epistemic virtue; many studies of this kind don't suffer from any deficit in this respect (see Sect. 7). The critical failure rather is how claims are processed in the corresponding community. What is missing, at times, is the epistemic attitude.

Open Access This article is distributed under the terms of the Creative Commons Attribution License which permits any use, distribution, and reproduction in any medium, provided the original author(s) and the source are credited.

\section{References}

Adam, M. (2008). Promoting disinterestedness of making use of bias? Interests and moral obligation in commercialized research. In M. Carrier, D. Howard, \& J. Kourany (Eds.), The challenge of the social and the pressure of practice. Science and values revisited (pp. 235-254). Pittsburgh: University of Pittsburgh Press.

Bacon, F. (1620). The New Organon (J. Spedding, R. L. Ellis \& D. D. Heath, trans). The Works VIII. Boston: Taggard and Thompson, 1863.

Biddle, J. (2007). Lessons from the Vioxx Debacle: What the privatization of science can teach us about social epistemology. Social Epistemology, 21, 21-39.

Brown, J. R. (2001). Who rules in science?. Cambridge Mass: Harvard University Press.

Carrier, M. (1981). Goethes Farbenlehre - ihre Physik und Philosophie. Zeitschrift für allgemeine Wissenschaftstheorie, 12, 210-225.

Carrier, M. (2006). Wissenschaftstheorie: Zur Einführung, Hamburg, Junius, rev. ed. 2011.

Carrier, M. (2008a). The aim and structure of methodological theory. In L. Soler, H. Sankey, \& P. Hoyningen-Huene (Eds.), Rethinking scientific change and theory comparison: Stabilities, ruptures, incommensurabilities? (pp. 273-290). Dordrecht: Springer.

Carrier, M. (2008b). Science in the grip of the economy: On the epistemic impact of the commercialization of research. In M. Carrier, D. Howard, \& J. Kourany (Eds.), The challenge of the social and the pressure of practice: Science and values revisited (pp. 217-234). Pittsburgh: University of Pittsburgh Press. 
Carrier, M. (2010). Research under pressure: Methodological features of commercialized science. In $\mathrm{H}$. Radder (Ed.), The commodification of academic research: Science and the Modern University (pp. 158-186). Pittsburgh: Pittsburgh University Press.

Carrier, M. (2011). Underdetermination as an epistemological test tube: Expounding Hidden values of the scientific community. Synthese, 180, 189-204.

Carrier, M., \& Finzer, P. (2010). Theory and therapy: On the conceptual structure of models in medical research. In A. Nordmann \& M. Carrier (Eds.), Science in the context of application. Methodological change, conceptual transformation, cultural reorientation (pp. 85-99). Dordrecht: Springer.

Collins, H. M., \& Evans, R. (2002). The third wave of science studies: Studies in expertise and experience. Social Studies of Science, 32, 235-296.

Douglas, H. (2000). Inductive risk and values. Philosophy of Science, 67, 559-579.

Fleck, L. (1936). Das Problem einer Theorie des Erkennens. In L. Schäfer \& T. Schnelle (Eds.), Ludwik Fleck. Erfahrung und Tatsache. Gesammelte Aufsätze (pp. 84-127). Frankfurt: Suhrkamp, 1983.

Hagner, M. (1999) Kluge Köpfe und geniale Gehirne. Zur Anthropologie des Wissenschaftlers im 19. Jahrhundert'. In idem (Ed.), Ansichten der Wissenschaftsgeschichte (pp. 227-268) Frankfurt: Fischer, 2001.

Hume, D. (1739/1740). A treatise of human nature. Oxford: Clarendon, 1888.

Kitcher, P. (1993). The advancement of science. Science without legend, objectivity without illusions. New York: Oxford University Press.

Kosso, P. (1992). Reading the book of nature. An introduction to the philosophy of science. Cambridge: Cambridge University Press.

Krimsky, S. (2003). Science in the public interest. Has the lure of profits corrupted biomedical research. Lanham: Rowman \& Littlefield.

Kuhn, T. S. (1977). Objectivity, value judgment, and theory choice. In Idem, The essential tension. Selected studies in scientific tradition and change (pp. 320-339). Chicago: University of Chicago Press.

Lakatos, I. (1970). Falsification and the methodology of scientific research programmes. In G. Worrall \& G. Currie (Eds.), The methodology of scientific research programmes (pp. 8-101). Cambridge: Cambridge University Press, 1978.

Laudan, L. (1984). Science and values. The aims of science and their role in scientific debate. Berkeley: University of California Press.

Levi, I. (1960). Must the scientist make value judgments? The Journal of Philosophy, LVII, 345-357.

Longino, H. E. (1990). Science as social knowledge: Values and objectivity in scientific inquiry. Princeton: Princeton University Press.

Longino, H. E. (1993). Essential tensions_-phase two: Feminist, philosophical, and social studies of science. In L. M. Antony \& C. Witt (Eds.), A mind of one's own. Feminist essays on reason and objectivity (pp. 257-272). Boulder: Westview Press.

Longino, H. E. (1995). Gender, politics, and the theoretical virtues. Synthese, 104, 383-397.

Longino, H. E. (2002). The fate of knowledge. Princeton: Princeton University Press.

Longino, H. E. (2008). Values, heuristics, and the politics of knowledge. In M. Carrier, D. Howard, \& J. Kourany (Eds.), The challenge of the social and the pressure of practice, science and values revisited (pp. 68-86). Pittsburgh: University of Pittsburgh Press.

McMullin, E. (1983) Values in science. In P. Asquith \& T. Nickles (Eds.), PSA 1982 II. Proceedings of the 1982 biennial meeting of the philosophy of science association: Symposia (pp. 3-28), East Lansing, Mich: Philosophy of Science Association.

McMullin, E. (2001). The impact of Newton's Principia on the philosophy of science. Philosophy of Science, 68, 279-310.

Merton, R. K. (1942). The normative structure of science. In idem, The sociology of science. Theoretical and empirical investigations (pp. 267-278). Chicago: University of Chicago Press, 1973.

Norton, J. (2008). Must evidence underdetermine theory? In M. Carrier, D. Howard, \& J. Kourany (Eds.), The challenge of the social and the pressure of practice: Science and values revisited (pp. 17-44). Pittsburgh: University of Pittsburgh Press.

Okruhlik, K. (1994). Gender and the biological sciences. In M Curd \& J. A. Cover (Eds.), Philosophy of science. The central issues (pp. 192-208). New York: Norton, 1998.

Popper, K. R. (1957) Science: conjectures and refutations. In idem, Conjectures and refutations. The growth of scientific knowledge (pp. 43-78). London: Routledge, 1963, 2002.

Popper, K. R. (1962). Die Logik der Sozialwissenschaften. In T. W. Adorno, et al. (Ed.), Der Positivismusstreit in der deutschen Soziologie (pp. 103-123). Neuwied: Luchterhand, 1971.

Quine, W. V. O., \& Ullian, J. S. (1978). The web of belief. New York: Random House.

Resnik, D. B. (1998). The ethics of science. An introduction. London: Routledge.

Rudner, R. (1953). The scientist qua scientist makes value judgments. Philosophy of Science, 20, 1-6. 
Ruphy, S. (2006). Empiricism all the way down: A defense of the value-neutrality of science in response to Helen Longino's contextual empiricism. Perspectives on Science, 14, 189-214.

Schweber, S. S. (1993). Physics, community and the crisis in physical theory. Physics Today, 11/1993, $34-40$.

Solomon, M. (2001). Social Empiricism. Cambridge Mass: MIT Press.

Stokes, D. E. (1997). Pasteur's quadrant. Basic science and technological innovation. Washington, D.C: Brookings Institution Press.

Weber, M. (1904). Die 'Objektivität' sozialwissenschaftlicher und sozialpolitischer Erkenntnis'. In idem, Gesammelte Aufsätze zur Wissenschaftslehre (pp. 146-214). Tübingen: Mohr, 1968.

Wilholt, T. (2006). Design-rules: Industrial research and epistemic merit. Philosophy of Science, 73, 66-89.

Wilholt, T. (2009). Bias and values in scientific research. Studies in History and Philosophy of Science, 40, 92-101.

Ziman, J. (2002). The continuing need for disinterested research. Science and Engineering Ethics, 8, $397-399$.

Ziman, J. (2003). Non-instrumental roles of science. Science and Engineering Ethics, 9, 17-27. 